\title{
Structure and Properties of Aliphatic Poly(carbonate) glycols with Different Methylene Unit Length
}

\author{
Tetsuo MAsubUChI ${ }^{* 1,3}$, Machiko SAKAI ${ }^{1}$, Ken $\mathrm{KoJIO}^{2}$, Mutsuhisa FurUKAWA ${ }^{1}$, and \\ Takeshi AOYAGI ${ }^{4}$ \\ ${ }^{1}$ Department of Materials Science, Graduate School of Science and Technology, Nagasaki University, \\ 1-14 Bunkyo-machi, Nagasaki 852-8521, Japan \\ ${ }^{2}$ Department of Materials Science and Engineering, Faculty of Engineering, Nagasaki University, \\ 1-14 Bunkyo-machi, Nagasaki 852-8521, Japan \\ ${ }^{3}$ Asahi Kasei Chemicals Corporation, \\ Hibiya-Mitsui Bldg., 1-2, Yurakucho 1-chome, Chiyoda-ku, Tokyo 100-8440, Japan \\ ${ }^{4}$ Asahi Kasei Corporation, \\ 2-1 Samejima, Fuji, Shizuoka 416-8501, Japan \\ *Corresponding author: masubuchi.tb@om.asahi-kasei.co.jp \\ Received June 11, 2007; Accepted September 10, 2007 \\ (C) 2007 The Society of Rubber Industry, Japan
}

\begin{abstract}
Aliphatic poly(carbonate) glycols (PC-glycols) with different methylene unit lengths were synthesized from ethylene carbonate and 1,3-propanediol, 1,4-butanediol, 1,5-pentanediol, 1,6-hexanediol, 1,7-heptanediol, 1,8octanediol, 1,9-nonanediol or 1,10-decanediol. The samples were coded 3002, 4002, 5002, 6002, 7002, 8002, 9002 and 10002 respectively, for each of these PC-glycols. Wide-angle X-ray diffraction (WAXD) and Differential Scanning Calorimetry (DSC) measurements were carried out to examine the structure of PC-glycols. A WAXD profile of 3002 showed only an amorphous halo with no particular crystalline peaks. Also, a DSC thermogram of 3002 showed the glass transition point but no melting peaks were observed. In the case of 5002, relatively weak WAXD peaks were observed, but no melting peaks were observed in the DSC thermogram. On the other hand, the other PC-glycols exhibited crystalline peaks in WAXD profiles and a melting peak in DSC thermograms. These results indicated that PC-glycols with odd numbered methylene unit length were more amorphous than those with even numbered methylene unit length.

PC-glycol 9002 and 10002 had two strong WAXD peaks, and these two peaks were located at almost the same $2 \theta$ angle. Furthermore, the position of these peaks was almost the same as those of linear polyethylene thus indicating that PC-glycol 9002 and 10002 had a similar crystal structure of that of linear polyethylene.
\end{abstract}

Keywords Aliphatic poly(carbonate) glycol, Methylene unit length, Wide-Angle X-ray Diffraction, Differential Scanning Calorimetry, Crystal structure, Polyurethane.

\section{Introduction}

Polyurethanes (PUs) are widely used as coating materials, adhesives, sealants, elastomers, foams, fibers and so $\mathrm{on}^{1-4)}$. PUs are generally synthesized from diisocyanate, polymer glycol and chain extender. The final structure of PUs consists of a soft segment formed with polymer glycol, a hard segment formed with diisocyanate and chain extender. A wide variety of PUs can be obtained by selecting these raw materials and can be designed for each application. Typical polymer glycols can be classified as polyether glycols, polyester glycols and poly(carbonate) glycols (PC-glycols). Among these polymer glycols, PCglycols are well known as the most durable polymer glycols, have better hydrolysis resistance, better heat stability, better oil and chemical resistances, and can be used for high performance PUs. Poly(hexamethylene carbonate) glycol (PHC) derived from 1,6-hexanediol is the most popular commercialized PC-glycol. Since PHC is highly crystallized at room temperature, $\mathrm{PHC}$ results in stiff PUs. Low crystallized PC-glycols were required and developed as aliphatic copolymerized PC-glycols ${ }^{5-12}$.

In this study, the aliphatic PC-glycols with different methylene unit length (molecular weight around 2000) were synthesized. WAXD and DSC measurements were carried out to investigate crystal structure of the PCglycols.

Furthermore, crystal structure of solid PC-glycols was 
simulated on a computer. Structural models of the PCglycols were made using the 'MS Modeling Crystal builder' (Accelrys Software Inc.), and WAXD pattern fitting was carried out using 'Reflex Powder Diffraction' (Accelrys Software Inc.).

\section{Experimental}

$420 \mathrm{~g}$ (5.52 mol) of 1,3-propanediol (Wako Chemical Co., Ltd., Japan) and $440 \mathrm{~g}(4.99 \mathrm{~mol})$ of ethylene carbonate (Wako Chemical Co., Ltd., Japan) were charged into a two-liter three-necked separable-flask equipped with a stirrer, a thermometer and a packed distillation column. After adding $0.01 \mathrm{~g}$ of lead acetate trihydrate (Wako Chemical Co., Ltd., Japan) as a catalyst, the mixture in the flask was heated with an oil bath under a pressure of 1.25 $\mathrm{kPa}$ at $140^{\circ} \mathrm{C}$. As a result, about $350 \mathrm{~g}$ of a distillate was obtained off for $12 \mathrm{~h}$. The distillate was mainly a mixture of ethylene glycol and ethylene carbonate. Thereafter, the pressure was reduced to $0.5 \mathrm{kPa}$ and temperature was elevated to $180^{\circ} \mathrm{C}$, and distillate removed (mainly 1,3 propanediol) for $4 \mathrm{~h}$. $361 \mathrm{~g}$ of viscous liquid at room temperature was obtained and identified as poly(trimethylene carbonate) glycol with hydroxyl value (OH value) of 59.30 (mg $\mathrm{KOH} / \mathrm{g})$. The number average molecular weight $\left(M_{\mathrm{n}}\right)$ calculated with $\mathrm{OH}$ value was 1892. This PC-glycol was denoted as 3002.

PC-glycol 4002, 5002, 6002, 7002, 8002, 9002 and 10002 were prepared in substantially the same manner as 3002 except that $5.52 \mathrm{~mol}$ of 1,4-buthanediol, 1,5penthanediol, 1,6-hexanediol, 1,7-heptanediol, 1,8octhanediol, 1,9-nonanediol or 1,10-decanediol was employed instead of 1,3-propanediol.

Melt viscosity of these PC-glycols was measured with a rotational viscometer (Tokyo Kasei Co., Ltd., Japan). A $1.5 \mathrm{ml}$ sample was placed on the stage and measured with a conical rotator at $80^{\circ} \mathrm{C}$. WAXD was investigated with the powdered sample of the PC-glycol at $25^{\circ} \mathrm{C}$ using RINT2200 (Rigaku Co., Ltd., Japan). WAXD profiles were obtained with a $2 \theta$ scan mode. Voltage and current of $\mathrm{X}$ ray source were set to be $40 \mathrm{kV}$ and $40 \mathrm{~mA}$, respectively. DSC measurements were performed to determine the glass transition temperature $\left(T_{\mathrm{g}}\right)$ and melting temperature $\left(T_{\mathrm{m}}\right)$ of the PC-glycols. DSC curves were obtained with DSC 8230 (Rigaku Co., Ltd., Japan) in the temperature range of -100 to $200^{\circ} \mathrm{C}$ at a heating rate of $10^{\circ} \mathrm{C} / \mathrm{min}$ under nitrogen atmosphere.

\section{Results and Discussion}

Table 1 shows properties of PC-glycols synthesized in this study. PC-glycols of 4002, 5002, 6002, 7002, 8002, 9002 and 10002 were in a solid state, while PC-glycol 3002 was in a liquid state at room temperature. Melt viscosity of these $\mathrm{PC}$-glycols at $80^{\circ} \mathrm{C}$ increased with decreasing the number of the methylene unit (Figure 1). Decreasing the number of the methylene unit means the increasing of carbonate content in the PC-glycol. This increasing of carbonate content in the PC-glycol increases the viscosity of the PC-glycol, because of the increasing interaction of carbonate groups which have strong dipole moment.

$T_{\mathrm{g}}$ and $T_{\mathrm{m}}$ of the PC-glycols were evaluated with DSC

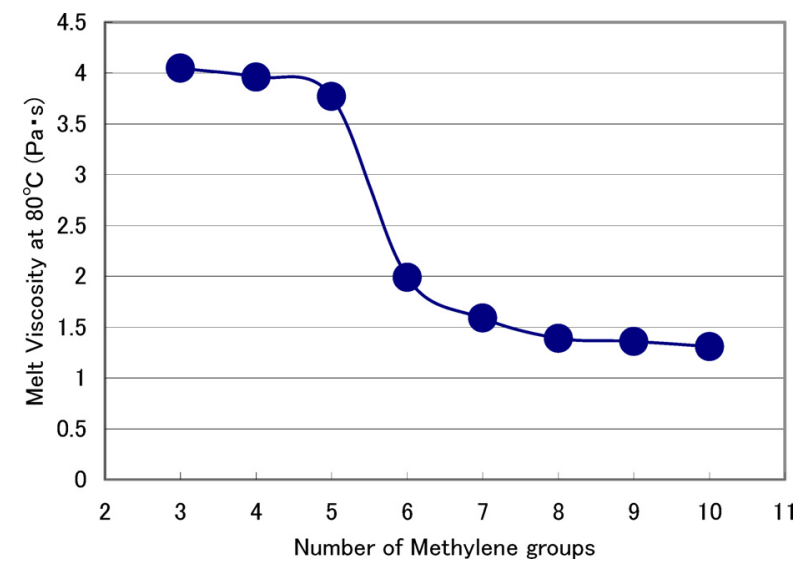

Figure 1. Effect of methylene unit length on melt viscosity.

Table 1. Basic properties of PC-glycols

\begin{tabular}{|c|c|c|c|c|c|c|}
\hline PC-glycol & $M_{\mathrm{n}}$ & Number of carbonate groups & State at $27^{\circ} \mathrm{C}$ & Viscosity at $80^{\circ} \mathrm{C}(\mathrm{Pa} \cdot \mathrm{s})$ & $T_{\mathrm{g}}\left({ }^{\circ} \mathrm{C}\right)$ & $T_{\mathrm{m}}\left({ }^{\circ} \mathrm{C}\right)$ \\
\hline 3002 & 1892 & 18 & Liquid & 4.05 & -31.5 & - \\
\hline 4002 & 1952 & 16 & Solid & 3.96 & -46.1 & 59.2 \\
\hline 5002 & 1945 & 14 & Solid & 3.77 & -49.0 & 41.1 \\
\hline 6002 & 1958 & 13 & Solid & 2.39 & -55.6 & 36.5 \\
\hline 7002 & 1972 & 12 & Solid & 1.59 & -62.4 & 48.7 \\
\hline 8002 & 1961 & 11 & Solid & 1.39 & - & 51.5 \\
\hline 9002 & 1951 & 10 & Solid & 1.36 & - & 53.0 \\
\hline 10002 & 1997 & 9 & Solid & 1.31 & - & 58.3 \\
\hline
\end{tabular}




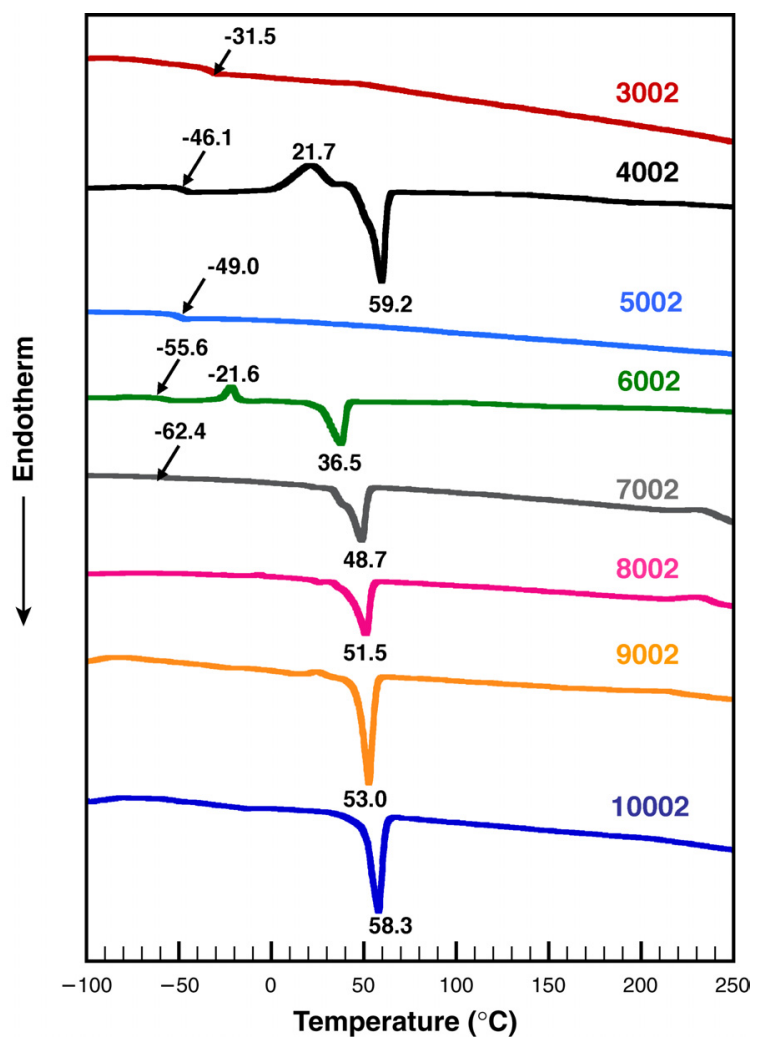

Figure 2. DSC thermograms of PC-glycols.

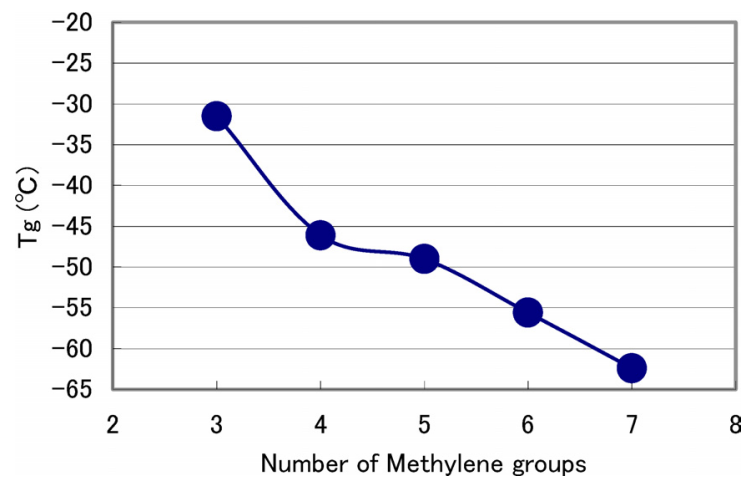

Figure 3. Glass transition temperature $\left(T_{\mathrm{g}}\right)$ of PC-glycols.

measurement (Figure 2). $T_{\mathrm{g}}$ increased with a decrease in the number of the methylene unit due to increasing interaction of the carbonate groups (Figure 3).

Melting peak of crystal was clearly observed for PCglycol $4002\left(59.2^{\circ} \mathrm{C}\right), 6002\left(36.5^{\circ} \mathrm{C}\right), 7002\left(48.7^{\circ} \mathrm{C}\right), 8002$ $\left(51.5^{\circ} \mathrm{C}\right), 9002\left(53.0^{\circ} \mathrm{C}\right)$ and $10002\left(58.3^{\circ} \mathrm{C}\right)$. On the other hand, no melting peak of crystal was observed for PCglycol 3002 and PC-glycol 5002. As discussed later, methylene unit length affected crystallinity of PC-glycols, with odd unit numbers resulting in a more amorphous state.

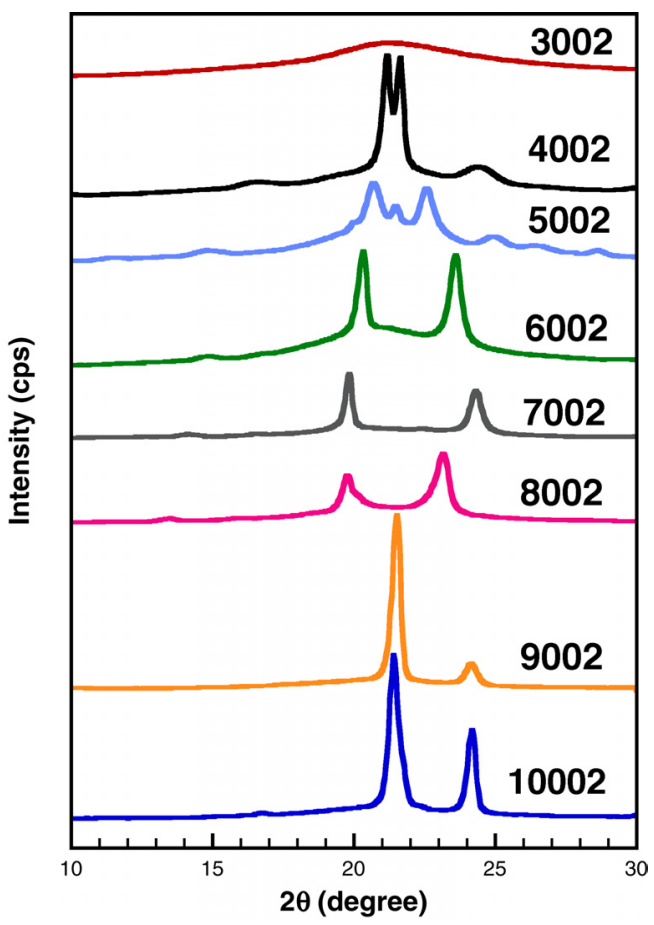

Figure 4. WAXD profile of PC-glycols.

In order to investigate the crystal structure of the PCglycols, WAXD was carried out. Figure 4 shows the WAXD profiles of PC-glycols. For PC-glycol 4002, 6002, 7002, 8002, 9002 and 10002, two main crystalline peaks were clearly observed. The position of these two main peaks were $2 \theta=20.8^{\circ}$ and $21.3^{\circ}$ for $4002,2 \theta=20.6^{\circ}$ and $22.5^{\circ}$ for $5002,2 \theta=20.3^{\circ}$ and $23.6^{\circ}$ for $6002,2 \theta=20.2^{\circ}$ and $24.3^{\circ}$ for $7002,2 \theta=19.8^{\circ}$ and $23.1^{\circ}$ for 8002 , $2 \theta=21.5^{\circ}$ and $24.1^{\circ}$ for $9002,2 \theta=21.4^{\circ}$ and $24.1^{\circ}$ for 10002. PC-glycol 5002 did show crystalline peaks, however, the intensity level of these peaks was weaker than those of other PC-glycols. In contrast, no crystalline peak was observed for PC-glycol 3002.

These results indicated that an odd number of the methylene unit length of PC-glycols were more amorphous than even numbered methylene unit lengths.

Computer pattern fitting and structure simulation of PCglycols were carried out. At first, structural model of PCglycol was made using 'MS Modeling Crystal builder'. Then, this model was imported to another software, 'Reflex Powder Diffraction', and the WAXD pattern was calculated. The WAXD pattern fitting result was feedbacked to the 'MS Modeling Crystal builder', and the crystal structure model was manually adjusted to agree with the observed WAXD data to determine the final structure. 


\section{(1) PC-glycol 4002}

Figure 5 is a computer pattern fitting of WAXD based on the molecular structure described in Figure 6. (amorphous background was canceled.) According to this structure model, the carbonate group was packed on the next carbonate group with reversed direction.
Unit cell is composed of a four-monomer unit. The carbonate group was located close to that of the next molecule. This short distance of the carbonate groups caused strong interaction of the carbonate groups, and provided the strong crystal peaks of WAXD. However, the methylene chain unit was not fully extended along "c" axis

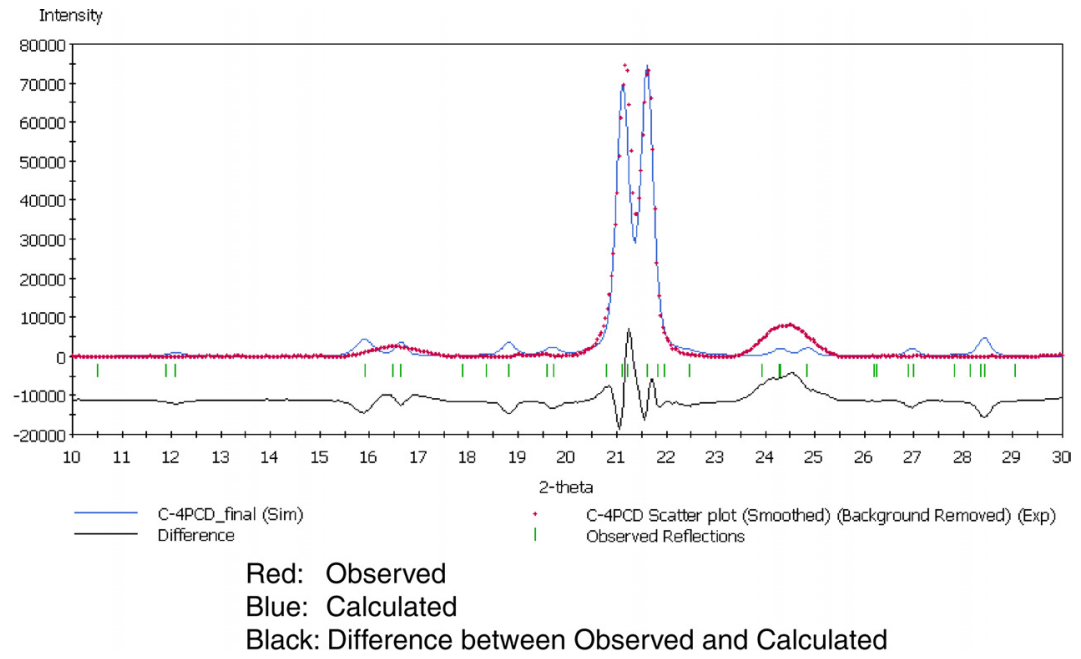

Figure 5. Computer WAXD pattern fitting of PC-glycol 4002.
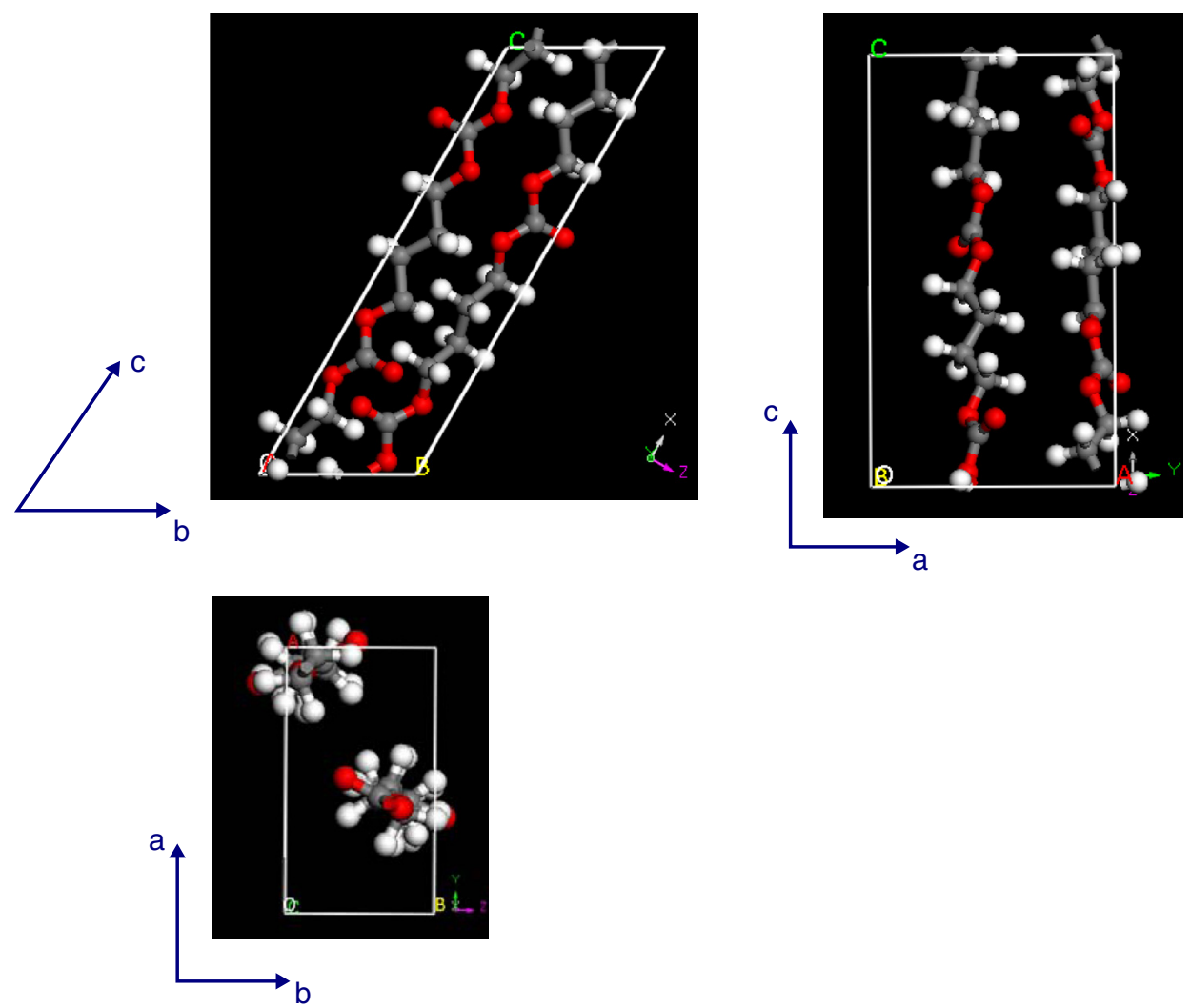

Figure 6. Structural model of PC-glycol 4002 determined with WAXD data simulation. 
due to the intra-molecule interaction of the carbonate groups. In case of the shorter methylene unit, the methylene unit might be compressed by the intra-molecule cohesion force of the carbonate groups, and gave the twisted structure of the methyene unit as described in Figure 6.

(2) PC-glycol 5002

Figure 7 is the computer pattern fitting of WAXD based on the molecular structure described in Figure 8. (amorphous background was canceled.) Main peaks of the simulated WAXD fitted well in the actual examination data. However, some small peaks were not simulated. In case of PC-glycol 5002, WAXD peaks were weaker than those of other PC-glycols, and crystal structure seems to be nonuniform. Some irregularity of the crystal structure might affect this result.

In the case of odd methylene unit length, the direction of the carbonate group was arranged in the same direction along the "c" axis. Reverse direction packing of the carbonate groups seems to be more stable than the same direction packing because of the strong dipole moment of the carbonate groups. In the case of PC-glycols with odd methylene unit lengths, carbonate groups repel each other due to the same directional arrangement of carbonate groups in the next molecule. As a result, carbonate groups could not locate close to the carbonate groups of the next molecule as described in Figure 8. This structural model couldn't make strong carbonate group affinity, and explains the reason for weak crystal peaks in PC-glycol 5002.

(3) PC-glycol 6002

The WAXD pattern fitting results is described in Figure 9. (Amorphous background was canceled.) Two main peaks and one weak peak were well simulated with the structural model described in Figure 10. The carbonate group is arranged in parallel, and PC-glycol molecule also arranged in parallel along "c" axis. The $\mathrm{C}-\mathrm{C}$ bonding of the methylene unit was arranged in the manner of trans conformation (TTTTT) and made the fully extended planar zigzag conformation. As for the difference of the structure between PC-glycol 6002 and 4002, methylene unit of PCglycol 6002 was well elongated, because longer methylene chain, weakened the intramolecular interaction of the carbonate groups.

Takahashi and Kojima investigated the crystal structure of poly(trimethylene carbonate $)^{13,14)}$. Poly(trimethylene carbonate) was amorphous in unextended state. When the film sample was extended 3 times, stretched poly(trimethylene carbonate) sample gave crystal peaks of WAXD, and crystal structure was investigated. In our study, 3002 was amorphous liquid at room temperature and no crystal peaks of WAXD were observed. The molecular weight of the sample examined by Takahashi and Kojima seems to be higher than that of our study. However, both results were agreed well at the point that poly(trimethylene carbonate) was amorphous in the relaxed state.

Takahashi and Kojima also investigated the crystal structure of poly(hexamethylene carbonate) ${ }^{13,14)}$. In this case, sample was stretched. The crystal structure of poly(hexamethylene carbonate) was orthorhombic and molecule was arranged with planar zigzag conformation along the "c" axis, and unit cell size was $a=8.81 \AA$, $\mathrm{b}=8.23 \AA, \mathrm{c}=21.47 \AA$. Our results also indicated the crystal structure with planar zigzag conformation. However, some detail was different (cell size, C-C bonding angle of rotation). In our study, unit cell size was estimated with WAXD peaks of $2 \theta=20.3^{\circ}$ and $23.6^{\circ}$, and obtained results was $\mathrm{a}=7.55 \AA, \mathrm{b}=6.15 \AA$, $\mathrm{c}=22.5 \AA$, and the $\mathrm{C}-\mathrm{C}$ bonding was arranged in the manner of trans conformation (TTTTT). The reason of the differences between the former study and our study is not clear at this moment. Some sample conditions differences (orientation) might have affected the results.

(4) PC-glycol 9002

The WAXD pattern fitting result is described in Figure 11. (Amorphous background was canceled.) Two main peaks were simulated with the structural model described in Figure 12.

Methylene unit length of PC-glycol 9002 was odd numbered. However, simulated conformation was completely different from PC-glycol 5002. WAXD peaks of the PC-glycol 9002 were stronger than those of PCglycol 5002, and this WAXD profile is similar to those of linear polyethylene. Segments of the methylene unit were packed in the manner of fully extended planar zigzag conformations along the "c" axis. Linear polyethylene has the crystal cell with $\mathrm{a}=7.406 \AA, \mathrm{b}=4.939 \AA, \mathrm{c}=2.547 \AA$, and unit cell angle of $90^{\circ}, 90^{\circ}$ and $90^{\circ}{ }^{15)}$. WAXD peaks of polyethylene were calculated $21.6^{\circ}$ (110) and $24.0^{\circ}$ (200) from the unit cell number of linear polyethylene as mentioned above. PC-glycol 9002 had the WAXD peaks of $21.5^{\circ}(110)$ and $24.1^{\circ}$ (200), and position of these WAXD peaks was close to those of linear polyethylene.

PC-glycol 10002 had almost the same WAXD profiles of PC-glycol 9002, and these results indicated that over methylene unit length nine, crystal structure was changed to the similar crystal structure of linear polyethylene due to the increasing of the hydrogen bond of the longer methylene unit. 


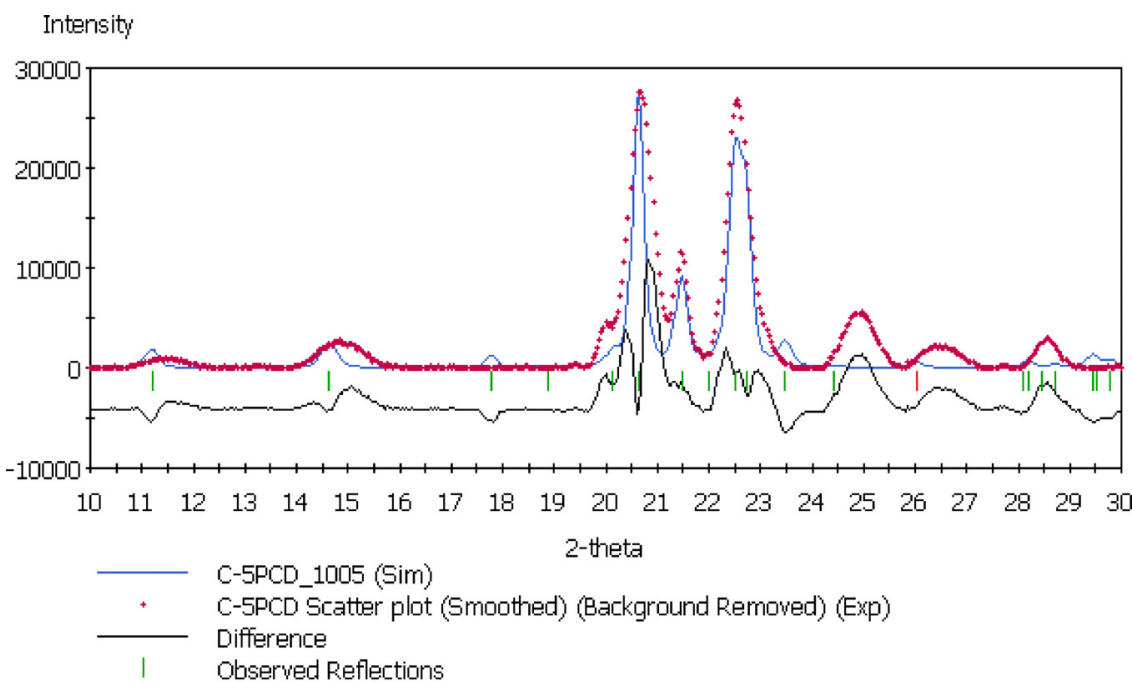

Red: Observed

Blue: Calculated

Black: Difference between Observed and Calculated

Figure 7. Computer WAXD pattern fitting of PC-glycol 5002.
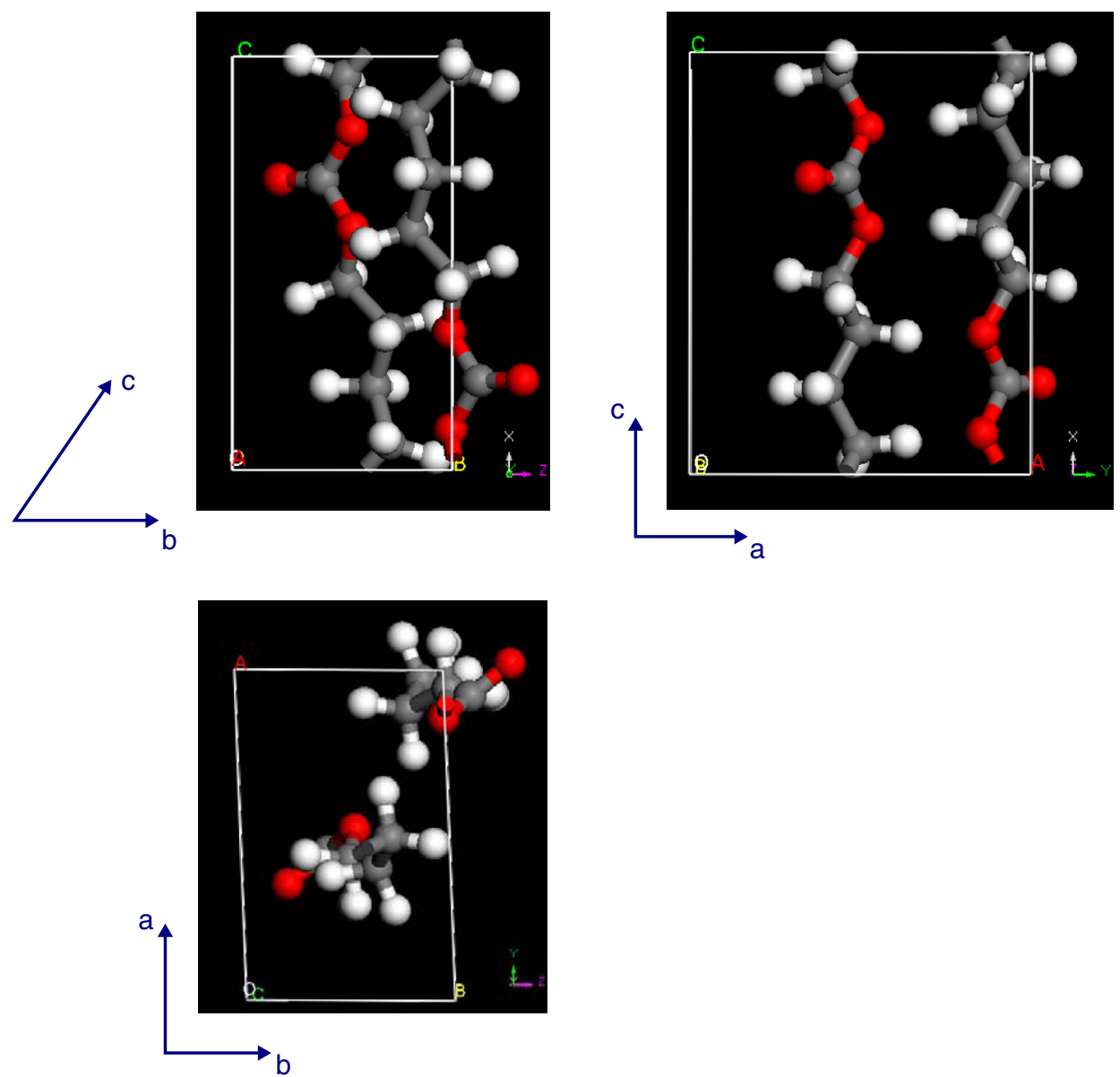

Figure 8. Structural Model of PC-glycol 5002 determined with WAXD data simulation. 


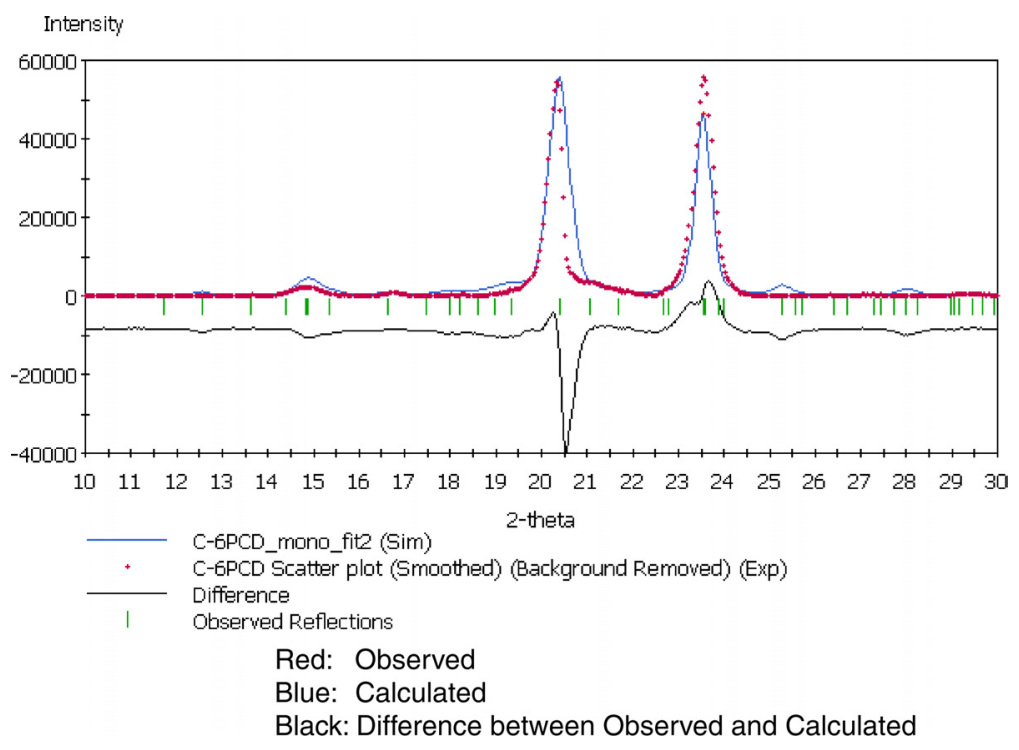

Figure 9. Computer WAXD pattern fitting of PC-glycol 6002.
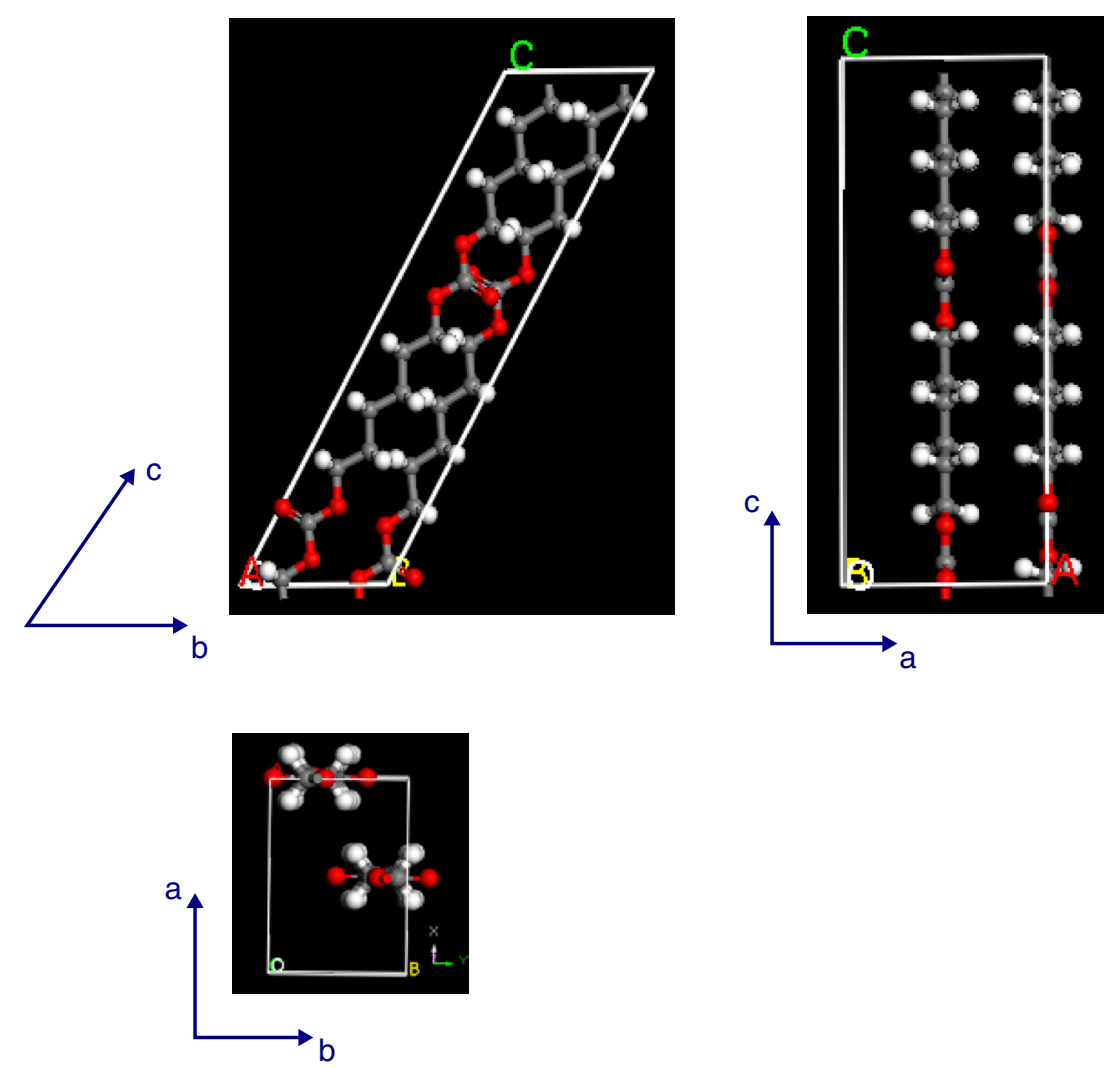

Figure 10. Structural Model of PC-glycol 6002 determined with WAXD data simulation. 


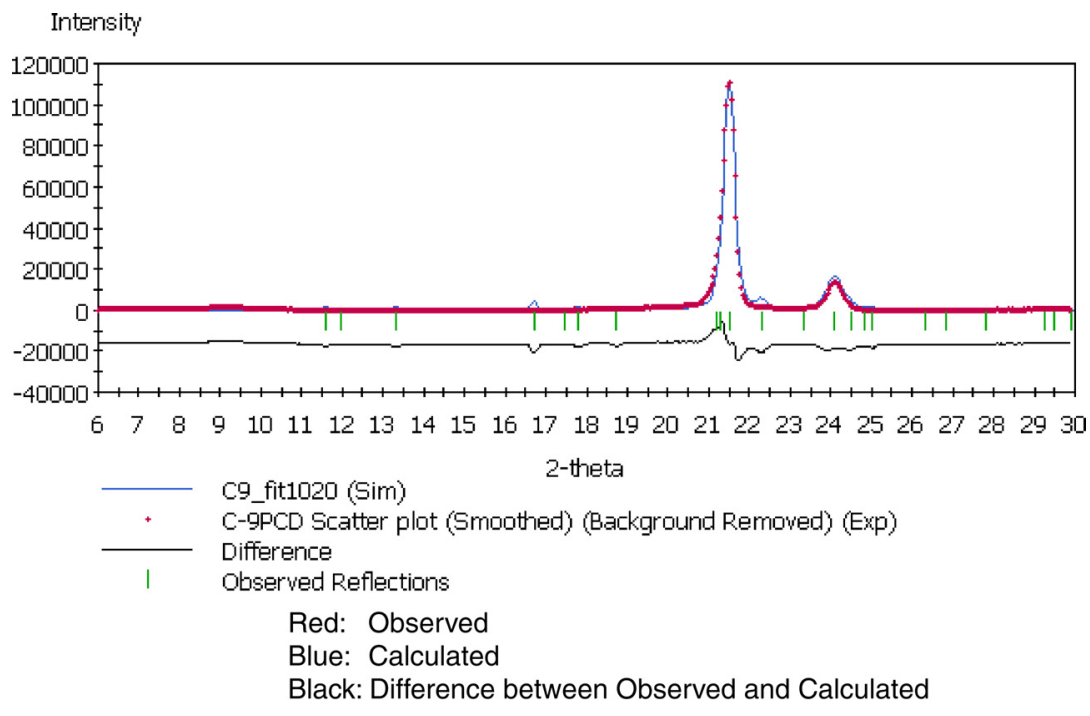

Figure 11. Computer WAXD pattern fitting of PC-glycol 9002.
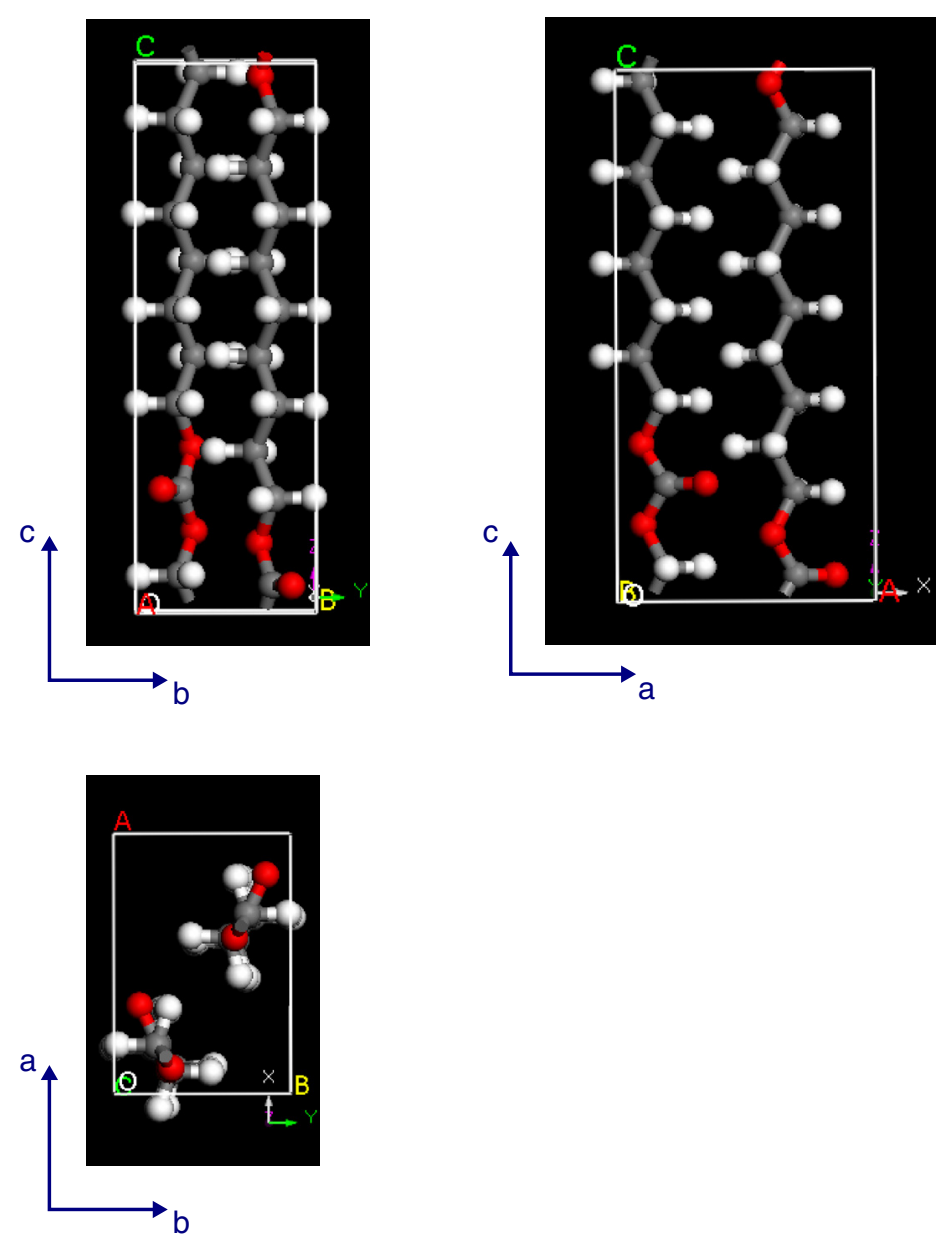

Figure 12. Structural Model of PC-glycol 9002 determined with WAXD data simulation. 
Table 2. Estimated crystal unit cell structure of PC-glycols

\begin{tabular}{ccccccccc}
\hline PC-glycol & Density $\left(\mathrm{g} / \mathrm{cm}^{3}\right)$ & $\mathrm{z}^{a)}$ & $\mathrm{a}(\AA)$ & $\mathrm{b}(\AA)$ & $\mathrm{c}\left({ }^{\circ}\right)$ & $\alpha\left(^{\circ}\right)$ & $\beta\left(^{\circ}\right)$ & $\gamma\left({ }^{\circ}\right)$ \\
\hline 4002 & 1.13 & 4 & 8.41 & 5.44 & 17.16 & 60 & 90 & 90 \\
5002 & 1.17 & 2 & 7.91 & 4.99 & 9.40 & 90 & 90 & 92.5 \\
6002 & 1.06 & 4 & 7.55 & 6.15 & 22.5 & 60 & 90 & 90 \\
7002 & 1.01 & 2 & 7.33 & 5.67 & 12.51 & 85 & 92 & 90 \\
8002 & 0.95 & 4 & 7.70 & 6.35 & 28.36 & 60 & 90 & 90 \\
9002 & 1.10 & 2 & 7.38 & 4.98 & 15.24 & 90 & 90 & 90 \\
10002 & 1.08 & 4 & 7.40 & 5.00 & 33.21 & 90 & 90 & 90 \\
Polyethylene & 1.00 & 2 & 7.417 & 4.945 & 2.547 & 90 & 90 & 90 \\
\hline
\end{tabular}

a) z: number of the monomer unit in the 1 unit cell.

Computer modeling of PC-glycol 7002, 8002 and 10002 was carried out in the same manner as PC-glycol 4002, 5002, 6002 and 9002. Calculated density, unit cell size and angles of the unit cell are summarized in the Table 2. PCglycol 4002, 6002, and 8002 had similar crystal cell structure composed of a four-monomer unit with cell angle of $\alpha=60^{\circ}, \beta=90^{\circ}$ and $\gamma=90^{\circ}$. On the other hand, unit cell of PC-glycol 5002 and 7002 were composed of a twomonomer unit, and the carbonate group was not located close to the carbonate group of the next molecule. These results indicate that differences of the even and odd number of methylene unit length affected the crystal structure of PC-glycol.

\section{Conclusions}

PC-glycols with different methylene unit lengths were synthesized. PC-glycol with odd methylene unit length gave no crystalline peak of WAXD (3002) or relatively weak WAXD peaks (5002). On the other hand, PC-glycols with even methylene unit length or longer methylene unit gave strong WAXD peaks and DSC melting peaks.

Structural models of PC-glycols were estimated with computer simulation method using WAXD data. PC-glycol 4002, 6002 and 8002 had similar crystal cell structure composed of a four-monomer unit with cell angle of $\alpha=60^{\circ}, \beta=90^{\circ}$ and $\gamma=90^{\circ}$. On the other hand, unit cells of PC-glycol 5002 and 7002 were composed of a twomonomer unit, and the carbonate group was not located close to the carbonate group of the next molecule. This structural model cannot make strong carbonate group affinity, and explained the reason of relatively weak crystal peaks. These results indicate that differences of the even and odd number of methylene unit length affected the crystal structure of PC-glycol due to the arrangement of the carbonate group. Over methylene unit length nine, crystal structure was changed to the similar crystal structure of linear polyethylene. In this case, longer methylene units dominate the crystal structure of PCglycol due mainly to the hydrogen bond of increasing methylene unit length.

These results indicated that the mechanical properties of PC-glycol based polyurethane might be controlled by changing the number of methylene chain length of the PCglycol.

\section{References}

1) Petrovic Z. S., Ferguson J.: Prog. Polym. Sci., 16, 695 (1991).

2) Furukawa M., Komiyama M., Yokoyama T.: Angew. Makromol. Chem., 240, 205 (1996).

3) Furukawa M., Hamada Y., Kojio K.: J. Polym. Sci. B, 41, 2355 (2003).

4) Kojio K., Fukumaru T., Furukawa M.: Macromolecules, 37, 3287 (2004).

5) Casetta C., Girelli D, Greco A.: Pitture Vernici Eur., 76 (1994).

6) Furukawa M.: J. Appl. Polym. Sci. Appl. Polym. Symp., 53, 61 (1994).

7) Fambri L., Penati A., Kolarik J.: Angew. Makromol. Chem., 209, 119 (1993).

8) Fambri L., Penani A., Kolarik J.: Polymer, 38, 835 (1997).

9) Yokota H., Matsuo M.: Jpn. Kokai Tokkyo Koho, JP 2000336139 (2000).

10) Koyama M., Shimizu A.: Jpn. Kokai Tokkyo Koho, JP 0431418 (1992).

11) Furukawa M., Kojio K.: Polyurethane Expo, 2003, 574 (2003).

12) Kojio K., Nonaka Y., Masubuchi T., Furukawa M.: J. Polym. Sci. B, 42, 4448 (2004).

13) Takahashi Y., Kojima R.: Macromolecules, 36, 5139 (2003).

14) Takahashi Y., Kojima R.: Polym. Preprints Jpn., 52(9), 1747 (2003).

15) Swan P. R.: J. Polym. Sci., 56, 403 (1962). 